\title{
Identification of QTLs for pod and kernel traits in cultivated peanut by bulked segregant analysis
}

\author{
Michael Gomez Selvaraj \\ Department of Plant and Soil Science \\ Texas Tech University \\ Lubbock, TX 79409, USA \\ Manivannan Narayana \\ Department of Oilseeds \\ Tamil Nadu Agricultural University \\ Coimbatore - 641 003, India
A. Michael Schubert
AgriLife Research
Texas A\&M System
1102 East FM 1294
Lubbock TX 79403, USA
Jamie L. Ayers
AgriLife Research
Texas A\&M System
1102 East FM 1294
Lubbock, TX 79403, USA
Michael R. Baring
AgriLife Research
Texas A\&M System
College Station, TX 77843, USA
Mark D. Burow*
AgriLife Research
Texas A\&M System and
Texas Tech University
1102 East FM 1294
Lubbock, TX 79403, USA
E-mail: mburow@tamu.edu \\ Department of Plant and Soil Science
}

Keywords: maturity, oil quantity, quality, SSR markers.

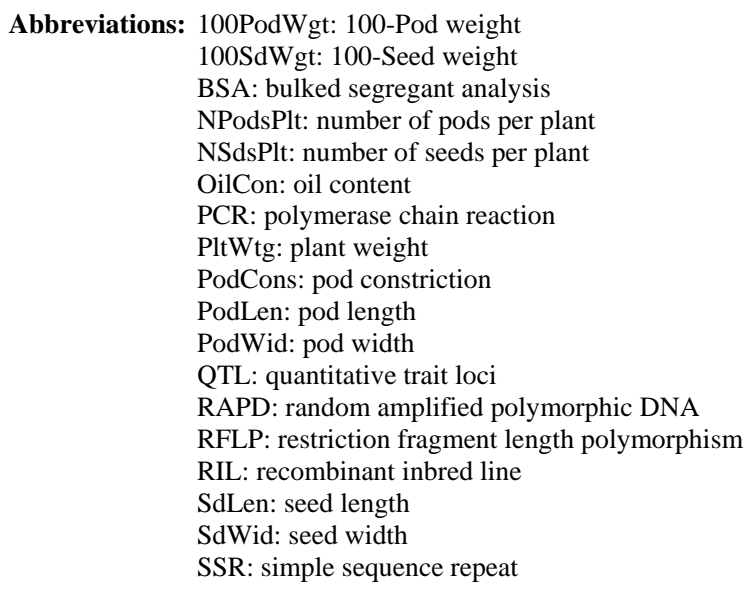

*Corresponding author 
Bulked segregant analysis was used to identify simple sequence repeat (SSR) markers associated with pod and kernel traits in cultivated peanut, to permit rapid selection of superior quality genotypes in the breeding program. SSR markers linked to pod and kernel traits were identified in two DNA pools (high and low), which were established using selected $F_{2: 6}$ recombinant individuals resulting from a cultivated cross between a runner (Tamrun OL01) and a Spanish (BSS 56) peanut. To identify quantitative trait loci (QTLs) for pod and kernel-related traits, parents were screened initially with 112 SSR primer pairs. The survey revealed $8.9 \%$ polymorphism between parents. Of ten SSR primer pairs distinguishing the parents, five (PM375, PM36, PM45, pPGPseq8D9, and Ah-041) were associated with differences between bulks for seed length, pod length, number of pods per plant, 100-seed weight, maturity, or oil content. Association was confirmed by analysis of segregation among $88 F_{2: 6}$ individuals in the RIL population. Phenotypic means associated with markers for three traits differed by more than $40 \%$, indicating the presence of QTLs with major effects for number of pods per plant, plant weight, and pod maturity. The SSR markers can be used for marker assisted selection for quality and yield improvement in peanut. To the best of our knowledge, this is the first report on the identification of SSR markers linked to pod - and kernel- related traits in cultivated peanut.

The cultivated peanut (Arachis hypogaea L.) is a major crop in most tropical and subtropical areas of the world. Peanut is an important oilseed, grown on approximately 24 million ha throughout the world (FAOSTAT, 2007). The genus Arachis is native to South America, with all the species having originated in Brazil, Bolivia, Argentina, Uruguay and Paraguay (Singh and Simpson, 1994). Although large germplasm collections of cultivated and wild species are available, peanut breeders have traditionally relied on crossing elite by elite germplasm for developing improved cultivars (Holbrook and Stalker, 2003). One major focus of peanut breeding programs is to increase grain yield, which is influenced by pod- and kernel-related traits. Gomes and Lopez (2005) reported that grain yield in cultivated peanut is influenced directly by the number of pods per plot and seed weight. A second major goal in peanut breeding is to improve edible seed quality. Early maturity is important for seed flavor, as well as escape from terminal drought and late-season diseases. Oil content and fatty acid composition are important for cooking, processing, oxidative stability (Moore and Knauft, 1989), coronary health (Kris-Etherton et al. 1999), and potentially for biofuel. Breeding efforts to improve various traits of the peanut, including oil, quality, disease/pest resistance, and yield, could be much more efficient and successful with the use of molecular markers.

Molecular marker analysis is useful for identification of genomic segments contributing to the genetic variance of a trait, and selection of superior genotypes. Marker analysis provides accurate genotypic information, which would be unavailable otherwise, giving a precision lacking with phenotypic measurements due to environmental interaction and experimental error (Altinkut et al. 2003). Molecular markers are sought for early and reliable selection of desired pod and kernel genotypes in breeding programs (Samizadeh et al. 2003).

Cultivated peanut exhibits a considerable amount of genetic variability for various morphological, physiological and agronomic traits. However, a low level of variation has been observed at the DNA level using random amplified polymorphic DNA (RAPD) (Halward et al. 1991; Subramanian et al. 2000; Mondal et al. 2005), inter simple sequence repeat (ISSR) (Raina et al. 2001), amplified fragment length polymorphism (AFLP) (Herselman, 2003), and SSR (Mace et al. 2006) markers. Of the major DNA marker types, SSR markers have been the most successful at identifying molecular variation within the cultivated peanut species (Hopkins et al. 1999; Ferguson et al. 2004). SSR as well as restriction fragment length polymorphism (RFLP) markers have the advantage of usually being codominant. However, SSR markers require smaller quantities of DNA than do RFLP-based markers (Powell et al. 1996), and analysis by SSR markers is quicker and does not involve use of radioisotopes.

With limited sequence information in peanut, few economically-important traits have been tagged using molecular markers, and many of these have been identified in interspecific introgression populations. Markers for resistance to root-knot nematode (Garcia et al. 1995; Burow et al. 1996; Choi et al. 1999), late leaf spot (Stalker and Mozingo, 2001; Mondal et al. 2005; Mace et al. 2006), the aphid vector causing groundnut rosette disease (Herselman et al. 2004), seed infection by Aspergillus flavus (Yong et al. 2005) and early leaf spot (Burow et al. 2008) have been indentified. However, no markers have been identified for pod-and kernel-related traits.

In peanut, four low density genetic maps have been published by utilizing variation among Arachis species, but no maps have been developed to date from cultivated $\mathrm{x}$ cultivated species crosses. The first genetic linkage map was developed using an $\mathrm{F}_{2}$ population of a cross between A-genome diploids $A$. stenosperma and $A$. cardenasii (Halward et al. 1993). A second map based on these parents used a $\mathrm{BC}_{1}$ population, and added 167 RAPD markers to a skeleton of 39 RFLP markers from the first map (Garcia et al. 2005). A third A-genome map was developed from the cross A. duranensis x A. stenosperma consisting of 170 SSR markers on 11 linkage groups, with a total map length of 1,231 cM (Moretzsohn et al. 2005). The largest map of peanut to date, and the only one to involve a parent from Arachis hypogaea, was constructed from a tetraploid cross of the cultivar Florunner $\mathrm{x}$ the synthetic amphidiploid TxAG-6 \{A. batizocoi x [A. cardenasii x A. diogoi] $\}^{4 x}$. A total of 370 RFLP loci were mapped onto 23 linkage groups, for a map distance of 2210 cM (Burow et al. 2001). 

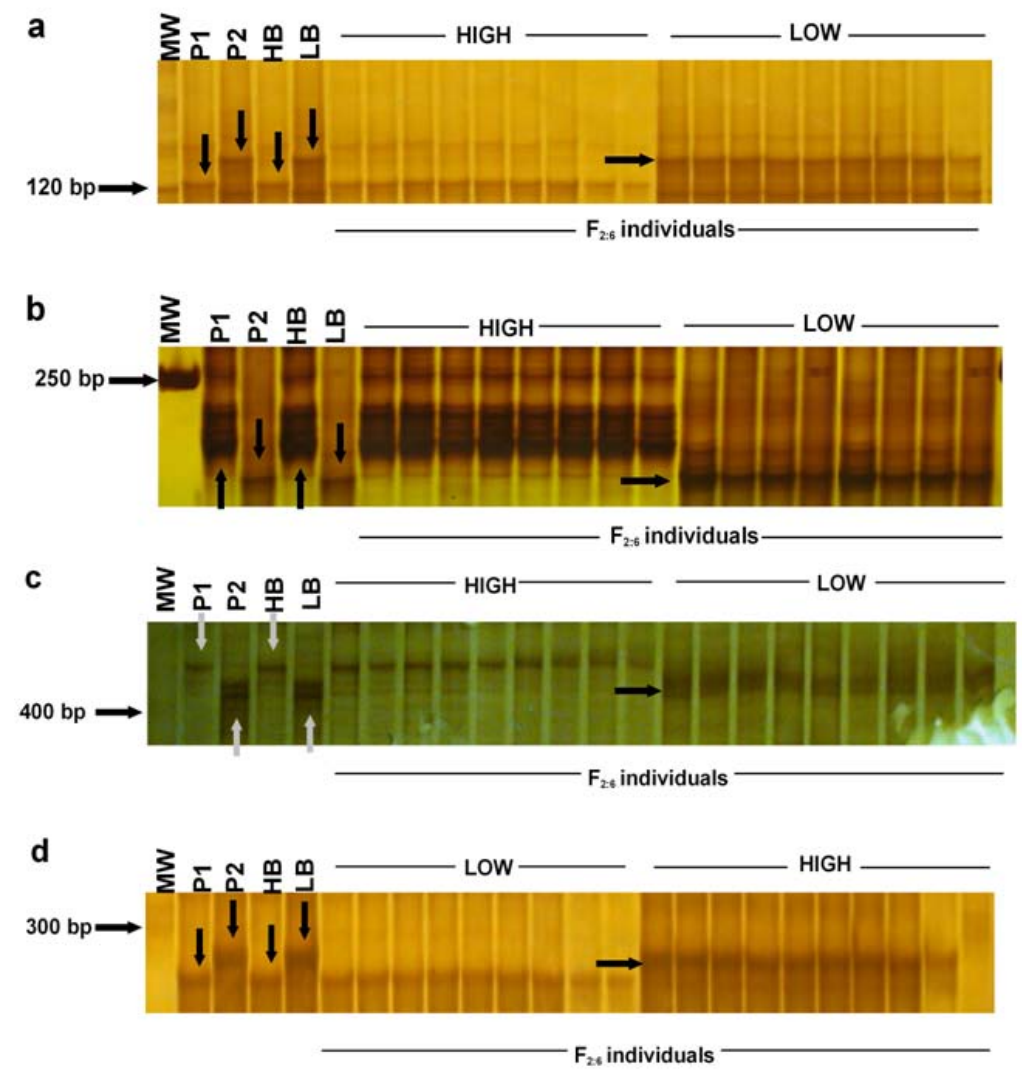

Figure 1. Bulked segregant analysis. BSA and co-segregation analysis of DNA from phenotypic extremes for:

(a) pod length with pPGPseq8D9

(b) mean seed length with PM375

(c) number pods per plant with Ah-041

(d) maturity with PM45.

Abbreviations: P1- Tamrun OL01, P2- BSS 56,HB- High value bulk, LB-Low value bulk.

Development of a linkage map from cultivated $\mathrm{x}$ cultivated peanut crosses is lacking due to the low polymorphism among cultivated peanut parents. However, one strength of bulked segregant analysis (BSA) is that it not does require a linkage map and can be used where insufficient polymorphism exists for a map. An additional advantage is that the approach relies on the dramatic reduction in the number of marker assays when compared to building a genetic map for the purpose of identifying markers associated with a phenotype (Wenzl et al. 2007). In this study, we have used the bulk segregant analysis technique in combination with SSRs to identify molecular marker(s) associated with pod and kernel traits in cultivated peanut. This is the first report that describes the association of SSR markers with pod and kernel related traits in cultivated peanut.

\section{MATERIALS AND METHODS}

\section{Population development}

A recombinant inbred $\mathrm{F}_{2: 6}$ population was developed at the Texas Agricultural Experiment Station, from a cross between Tamrun OL01 and BSS 56. The female parent Tamrun OL01 is a high-oleic runner variety (A. hypogaea ssp. hypogaea var. hypogaea) released by the Texas A\&M Agricultural Experimental Station (Simpson et al. 2003). Tamrun OL01 is a heat-susceptible variety with maturity of 140 days in south Texas and has a high oleic:linoleic ratio. The genotype BSS 56 is a Spanish bunch variety (A. hypogaea ssp. fastigiata var. vulgaris) originating from Africa, and is heat-tolerant and matures 120 days after planting. The initial cross was made at College Station, Texas in 2000. The $F_{2}$ single plants were forwarded up to the $F_{6}$ generation by single seed descent. The $F_{2: 4}$ generation was planted at the Western Peanut Growers Research Farm at Denver City, Texas in 2002. In 2006, $F_{2: 6}$ plant rows were grown at the Texas Tech Farm, Lubbock, Texas. A total of 88 recombinant $\mathrm{F}_{2: 6}$ inbred lines (RILs) were used in the present study.

\section{Phenotypic evaluation}

Observations were recorded in $\mathrm{F}_{2: 4}$ progeny for number of pods per plant (NPodsPlt), number of seeds per plant (NSdsPlt), plant weight (PltWtg) and percentage of mature 


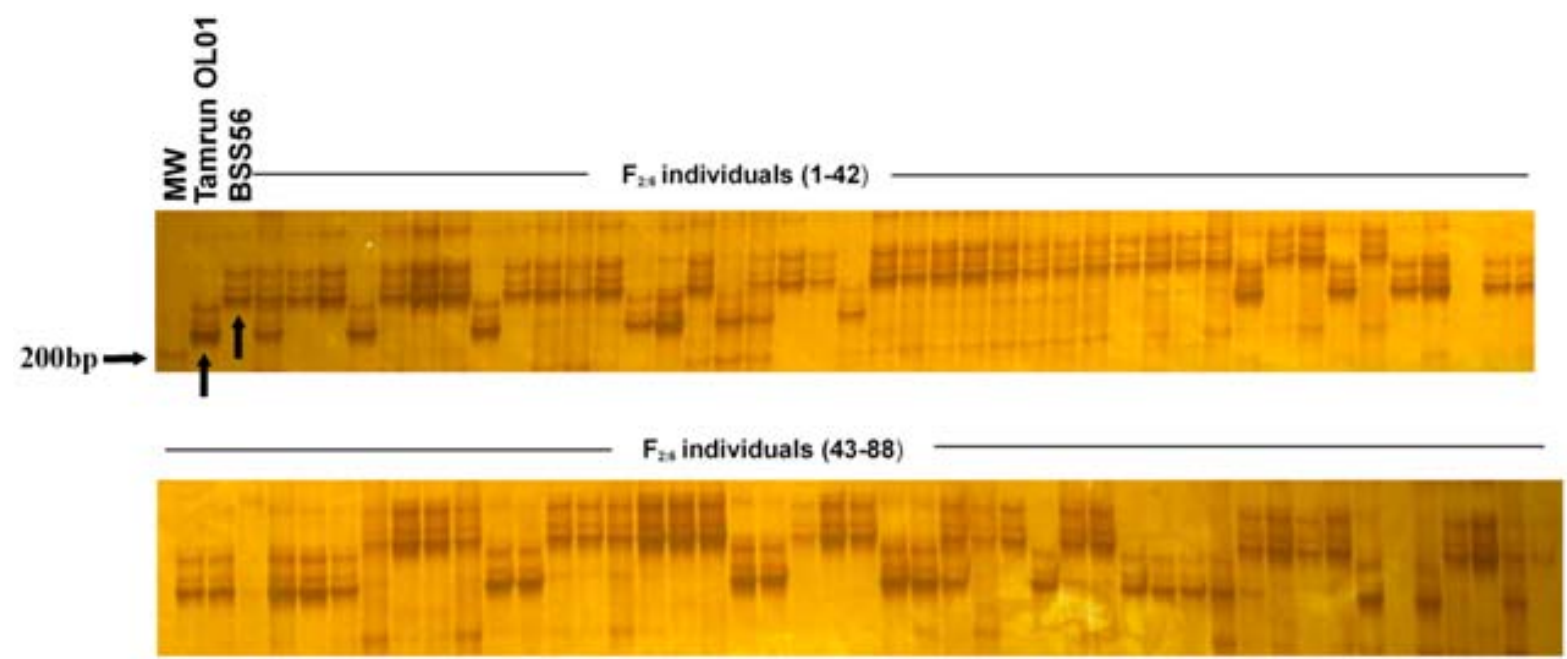

Figure 2. Segregation pattern of SSR marker PM375 linked to pod length, mean seed length, and 100 seed weight on $88 F_{2: 6}$ individuals from the RIL population derived from a cross between Tamrun OL01 and BSS 56. Abbreviations: P1- Tamrun OL01, P2- BSS 56, HB- High value bulk, LB-Low value bulk.

pods (\% maturity) as determined by the hull scrape method (Williams and Drexler, 1981) during 2002. Observations on pod constriction (PodCons), 100-pod weight (100PodWgt), 100-seed weight (100SdWgt), seed length (SdLen), seed width (SdWid), pod length (PodLen), pod width (PodWid), and oil content (OilCon) were made on the $\mathrm{F}_{2: 6}$ generation during 2006. Oil content was determined on seed samples using a Bruker NMR spectrometer.

\section{SSR analysis}

Young leaves from greenhouse-grown plants of the parental genotypes and field-grown $F_{2: 6}$ plants were harvested, frozen in liquid nitrogen, and stored at $-80^{\circ} \mathrm{C}$. Stored leaf tissues were used for DNA extraction. The DNA was extracted using the Qiagen Inc (Valencia, CA) mini Plant Extraction Kit. Purified DNA was dissolved in TE $(10 \mathrm{mM}$ Tris HCl, $1.0 \mathrm{mM}$ sodium EDTA, pH 8.0) buffer. The quantity and quality of DNA were assessed by electrophoresis in $0.8 \%$ agarose gels with known concentrations of phage lambda DNA.

Polymorphism between parents was identified by screening Tamrun OL01 and BSS 56 with 112 SSR primer pairs developed for cultivated peanut. Primer pairs were selected from various published sources (Hopkins et al. 1999; Ferguson et al. 2004; Moretzsohn et al. 2004). Polymerase chain reaction (PCR) mixtures $(10 \mu \mathrm{l})$ contained $40 \mathrm{ng}$ of template DNA, 1 X PCR buffer, $2 \mathrm{mM} \mathrm{MgCl}, 0.25 \mathrm{mM}$ of each dNTP, $5 \mu \mathrm{M}$ of each (forward and reverse) primer and 0.5 unit of Hot Star Taq polymerase (Qiagen Inc, Valencia, CA). Amplification was performed in an MJ Research PTC 100 Thermal Cycler (BioRad, Hercules CA). DNA samples were denatured initially at $94^{\circ} \mathrm{C}$ for $3 \mathrm{~min}$, then subjected to the following 20 cycles: $94^{\circ} \mathrm{C}$ for $30 \mathrm{sec}, 63^{\circ} \mathrm{C}$ for $30 \mathrm{sec}$ with a decrement of $0.5^{\circ} \mathrm{C}$ per cycle, and $70^{\circ} \mathrm{C}$ for $1 \mathrm{~min}$.
This was followed by another 20 cycles of $94^{\circ} \mathrm{C}$ for $15 \mathrm{sec}$, $55^{\circ} \mathrm{C}$ for $30 \mathrm{sec}$, and $70^{\circ} \mathrm{C}$ for $1 \mathrm{~min}$. A 10 min extension was performed at $72^{\circ} \mathrm{C}$ as the last step. Amplified products were analyzed using 6\% (19:1, acrylamide: bisacrylamide) non-denaturing polyacrylamide gel (Gomez et al. 2008). Electrophoresis was performed at 350 volts DC for 3.5 hrs in a Mega-gel High Throughput Vertical Unit (CBS Scientific, Del Mar, CA). Silver staining followed Benbouza et al. (2006).

\section{Bulked segregant analysis}

Two bulks of the extremes phenotypes (high and low) were used for the bulked segregant analysis (Michelmore et al. 1991). For each of twelve pod and kernel-traits (Table 1), high and low phenotypic bulks were made by bulking equal quantities of DNA from 8-10 respected $F_{2: 6}$ or $F_{2: 4}$ individuals from each phenotypic extreme. Primer pairs that distinguished between parents were used to amplify DNA from bulked samples, and patterns were observed for banding differences between the high and low phenotype bulks for each trait.

Verification of apparent marker association with traits in the BSA analysis was performed by amplification of $88 \mathrm{~F}_{2: 6}$ individuals from the segregating population. Statistical analysis of results was performed as given below.

\section{Statistical analysis}

Mean, variance, and Pearson correlation coefficients were calculated using SYSTAT 7.0 (SYSTAT Inc., Chicago, IL). For determination of segregation distortion, a chi-square test was performed for each marker using the $88 \mathrm{~F}_{2: 6}$ individuals of the segregating recombinant inbred line (RIL) population. The null hypothesis was that marker 
Identification of QTLs for Pod and kernel traits in cultivated peanut by bulked segregant analysis

Table 1. Mean, range and variance of $F_{2: 6}$ and $F_{2: 4}$ populations of Tamrun OL01 x BSS 56.

\begin{tabular}{|c|c|c|c|c|c|}
\hline Traits & $\begin{array}{l}\text { Tamrun OL01 } \\
\text { Mean }\end{array}$ & BSS 56 Mean & \multicolumn{3}{|c|}{$\begin{array}{c}F_{2: 6} \text { and } F_{2: 4} \text { populations of Tamrun OL01 } x \\
\text { BSS } 56\end{array}$} \\
\hline & & & Mean & Range & SD \\
\hline PodCons $\left(F_{2: 6}\right)$ & 7 & 3 & 4.46 & $3.00-9.00$ & 1.46 \\
\hline 100PodWgt $\left(F_{2: 6}\right)(g)$ & 210 & 138 & 179.11 & $87.50-300.40$ & 44.25 \\
\hline $100 S d W g t\left(F_{2: 6}\right)(g)$ & 80.60 & 55.15 & 70.27 & $39.90-102.80$ & 15.06 \\
\hline SdLen $\left(F_{2: 6}\right)(\mathrm{mm})$ & 15.19 & 12.99 & 14.96 & $10.72-19.04$ & 1.93 \\
\hline $\operatorname{SdWid}\left(F_{2: 6}\right)(\mathrm{mm})$ & 10.55 & 8.25 & 9.61 & $7.66-13.71$ & 1.00 \\
\hline PodLen $\left(F_{2: 6}\right)(\mathrm{mm})$ & 28.39 & 32.34 & 31.07 & 21.09-44.91 & 4.24 \\
\hline PodWid $\left(F_{2: 6}\right)(\mathrm{mm})$ & 12.12 & 14.00 & 13.60 & $10.08-17.67$ & 1.73 \\
\hline NPodsPIt $\left(F_{2: 4}\right)$ & 55.6 & 53.57 & 50.72 & $10.0-123.0$ & 28.46 \\
\hline NSdsPIt $\left(F_{2: 4}\right)$ & 73.4 & 76 & 50.83 & $7.00-106.00$ & 27.09 \\
\hline OilCon $\left(F_{2: 6}\right) \%$ & 48.37 & 48.32 & 46.41 & $39.84-51.60$ & 2.48 \\
\hline Maturity $\left(F_{2: 4}\right) \%$ & 43.3 & 93.4 & 60.81 & $0.00-100.00$ & 27.78 \\
\hline PltWgt $\left(F_{2: 4}\right)(g)$ & 91.6 & 59.2 & 64.06 & $11.10-163.50$ & 38.20 \\
\hline
\end{tabular}

alleles segregated in a 1:1 ratio, and the statistical test was performed at the $p=0.05$ level of significance.

Single marker analysis (SMA) was performed using the GLM module in SYSTAT to detect the association of markers with various pod and kernel traits. To reduce the probability of false positives, a Bonferroni-experiment-wise p-value was used for each marker trait association tested, dividing 0.05 by the number of comparisons made. $\mathrm{A} \mathrm{p}=$ 0.007 significance threshold was used for each marker initially distinguishing phenotypes among bulks. The coefficient of determination $\left(\mathrm{R}^{2}\right)$ was used as a measure of the magnitude of association. Mean marker phenotypes were calculated as least square means for each marker allele.

\section{RESULTS}

\section{Phenotypic value of pod and kernel related parameters}

Significant variation was found among the RILs and the parents for various pod and kernel related traits. The mean, range and variance of $\mathrm{F}_{2: 4}$ and $\mathrm{F}_{2: 6}$ populations of Tamrun OL01/BSS 56 are given in Table 1. Correlation analysis was carried out to find the association between various pod and kernel traits (Table 2). Mean seed length had a highly significant positive association with 100-seed weight $(\mathrm{r}=$ $0.811, \mathrm{p}<0.001)$ and mean pod length $(\mathrm{r}=0.853$, $\mathrm{p}<$ 0.001 ). Number of pods had a highly significant positive correlation with plant weight $(0.882, \mathrm{p}<0.001)$.

\section{Polymorphism between parents}

A total of 112 SSR primer pairs were screened to identify polymorphism among the parental genotypes BSS 56 and Tamrun OL01. Of these, all 112 amplified bands in both parents, and a total of 228 bands were amplified, for an average of 2.0 bands per primer pair. Ten primers were polymorphic between the parents, for a polymorphism percentage of $8.9 \%$.

\section{Identification of SSR markers associated with phenotype extremes among bulks}

The ten primer pairs that produced patterns distinguishing the parents were surveyed on bulked DNA from the extremes of different pod and kernel related traits analyzed in the present study. Of the ten SSR primer pairs, five primer pairs produced alleles that discriminated between the bulked extremes for at least one trait (Figure 1). These primer pairs were PM375 (which was associated with 
Table 2. Pearson correlations among pod and kernel traits.

\begin{tabular}{|c|c|c|c|c|c|c|c|c|c|c|c|c|}
\hline & PctOil & PodCons & 100PodWgt & 100SdWgt & SdLen & SdWid & PodLen & PodWid & PltWtg & NPodsPlt & NSdsPIt & $\begin{array}{c}\% \\
\text { Maturity }\end{array}$ \\
\hline PctOil & 1.000 & & & & & & & & & & & \\
\hline PodCons & -0.229 & 1.000 & & & & & & & & & & \\
\hline 100PodWgt & -0.177 & 0.185 & 1.000 & & & & & & & & & \\
\hline 100SdWgt & -0.137 & 0.145 & 0.920 *** & 1.000 & & & & & & & & \\
\hline SdLen & -0.217 & 0.190 & $0.759 * \star \star$ & 0.811 *** & 1.000 & & & & & & & \\
\hline SdWid & 0.036 & 0.159 & 0.662 *** & $0.734 * * *$ & 0.415 * & 1.000 & & & & & & \\
\hline PodLen & -0.276 & 0.354 & 0.785 *** & $0.765 * \star \star$ & 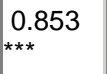 & 0.404 & 1.000 & & & & & \\
\hline PodWid & -0.343 & 0.171 & $0.815 * \star \star$ & $0.842 * * *$ & $\underset{\star \star \star \star}{0.763}$ & $\underset{* \star \star}{0.572}$ & $\underset{\star \star \star \star}{0.732}$ & 1.000 & & & & \\
\hline PItWtg & -0.103 & 0.200 & 0.079 & 0.065 & 0.096 & 0.043 & 0.042 & 0.057 & 1.000 & & & \\
\hline NPodsPIt & -0.050 & 0.115 & -0.233 & -0.262 & -0.208 & -0.201 & -0.257 & -0.240 & $\underset{\star \star *}{0.882}$ & 1.000 & & \\
\hline NSdsPIt & 0.063 & -0.019 & -0.093 & -0.106 & -0.180 & -0.087 & -0.132 & -0.202 & $\begin{array}{l}0.695 \\
\star \star \star\end{array}$ & 0.747 *** & 1.000 & \\
\hline$\%$ Maturity & 0.021 & 0.048 & -0.212 & -0.273 & -0.224 & -0.200 & -0.242 & -0.275 & 0.022 & 0.075 & 0.114 & 1.000 \\
\hline
\end{tabular}

differences in mean seed length, pod length and 100-seed weight); pPGPseq8D9 (pod length); Ah-041 (plant weight and number of pods per plant); PM45 (percentage of mature pods); and PM36 (oil content) (Table 3).

\section{Verification of markers in segregating $F_{2: 6}$ individuals}

The five markers putatively associated with phenotypic traits, based on the analysis of bulked extremes, were screened against the $88 \quad \mathrm{~F}_{2: 6}$ individuals in the RIL population (Figure 2). None of the markers demonstrated segregation distortion, as none deviated significantly from the expected 1:1 segregation ratio among the RILs, as evidenced by chi-square analysis (data not shown). The ANOVA of these markers confirmed all five were associated with the traits indicated by bulked segregant analysis. For example, the association of percentage of mature pods with the PM45 marker genotypes had a strongly significant association, with $\mathrm{p}<0.0001$, and explained $17.69 \%$ of total phenotypic variance for maturity (Table 3).

Several of the markers had large effects on phenotype (Table 3). For two traits, the phenotypic mean of individuals possessing one marker allele was $>40 \%$ greater than the mean of individuals possessing the other allele. For
PM45, plants having the Tamrun OL01 allele averaged $51.86 \%$ mature pods, whereas plants with the BSS 56 allele had $74.38 \%$ mature pods. Likewise, marker Ah-041 had a major influence on the number of pods per plant and plant weight, with 60.24 and 40.65 pods per plant, and plant weights of 76.5 and $53.4 \mathrm{~g}$ for plants with the Tamrun OL01 and BSS 56 alleles, respectively. The effect of SSR marker PM36 on oil content was also strong, explaining a difference of $1.8 \%$ point in oil percentage in seeds.

Co-segregation analysis revealed that differences between the bulked extremes and the respective individuals were very clear (Figure 1). For all but two traits, there was no apparent recombination between marker and trait in the high or low bulks, suggesting a close linkage. However, for two traits, namely pod length and oil content, there was 11.5 and $16.6 \%$ recombination between trait and markers within the high and low bulks, (Table 3).

\section{DISCUSSION}

\section{Significance of markers}

In this study, molecular markers linked to pod and kernel traits in cultivated peanut were identified by BSA using SSR markers. Markers for seed and pod length, seed weight, number of pods per plant, plant weight, pod 
maturity, and oil content were identified. One QTL was identified for each of these traits, except pod length, for which two QTLs were identified. To our knowledge, this is the first report of QTLs for pod and kernel related traits in peanut.

According to Collard et al. (2005), QTLs accounting for more than $10 \%$ of phenotypic variation $\left(\mathrm{R}^{2}\right)$ are major QTLs. In the present study, all the reported QTLs were major except for the two QTLs for pod length (Table 3). Among the five linked SSR markers, the PM45 QTL for pod maturity accounted for the highest percentage of total phenotypic variation (17.7\%), followed by Ah-041 and PM 375 , which explained, each, $12.5 \%$ of total phenotypic variation for number of pods and seed length, respectively. Given the size of the RIL population (88 individuals), it is expected that only one or two QTLs of major significance would be identified for each trait (Beavis, 1998). It should be noted that no QTLs were identified for pod constriction, 100-pod weight, seed width, pod width and number of seeds per plant. Given that only ten markers differentiated between the parents, it was not expected that there would be sufficient coverage of the genome to identify QTLs for all traits tested. Given a genome length of approx. $2200 \mathrm{cM}$ (Burow et al. 2001), and ten polymorphic markers, the upper limit of $18 \%$ of the genome could expect to be covered, assuming that BSA allows identification of markers up to $20 \mathrm{cM}$ from a gene in either direction; this would be in approximate agreement with the ability to identify markers with an estimated $16.6 \%$ crossover in the case of PM36 and seed oil percentage.
Bulked segregant analysis, combined with selective genotyping, permitted identification of the first QTLs for pod- and kernel-related traits in peanut, both by permitting analysis in absence of a linkage map, and by reducing the degree of effort needed to identify associations between markers and phenotypes.

Segregation of the QTL-associated alleles was as expected, and indicates a lack of detected segregation distortion or epistatic interactions. The RIL population was expected to have a 1:1 ratio at each marker for parental alleles. The five QTL-associated SSR markers all approximately fit the expected segregation ratio. This suggests that it may be possible to use these SSR markers (Table 3) for breeding high yielding peanut genotypes for the desired seed quality traits without complications arising from segregation distortion or potentially-associated epistatic interactions.

\section{Linkage of markers to multiple traits}

In this study, two SSR markers were linked to more than one phenotypic trait (Table 3). Bands amplified by primer PM375 were linked to seed length, pod length, and 100seed weight; and primer Ah-041 amplified bands linked to number of pods and plant weight. This indicates that the chromosomal regions identified by these markers may contain linked genes or a gene with pleiotropic effects on multiple traits. This co-location of QTLs was clearly brought out by correlation analysis, where seed length had positive significant association with 100 -seed weight, and pod length and number of pods showed high significant

Table 3. Significant SSR markers by BSA analysis that detect phenotypic variation with pod-related traits by variance analysis in the RIL population, and phenotypic means of significant high and low bulks and their mean value for each marker allele.

\begin{tabular}{|c|c|c|c|c|c|c|c|c|}
\hline Trait & SSR marker & P-value & $\mathbf{R}^{2} \%$ & $\begin{array}{c}\text { Recombination } \\
\%\end{array}$ & $\begin{array}{c}\text { High bulk } \\
\text { phenotypic mean* }\end{array}$ & $\begin{array}{c}\text { Low bulk } \\
\text { phenotypic } \\
\text { mean* }\end{array}$ & $\begin{array}{c}\text { Phenotypic } \\
\text { mean value } \\
\text { of TamRun } \\
\text { OL01 allele } \\
\text { in } \mathbf{F}_{2: 4} \text { or } \mathbf{F}_{2: 6}\end{array}$ \\
$\begin{array}{c}\text { Phenotypic } \\
\text { BSS } 56 \text { allele } \\
\text { in } \mathbf{F}_{2: 4} \text { or } \mathbf{F}_{2: 6}\end{array}$ \\
\hline SdLen (mm) & PM375 & 0.001 & 12.45 & 0 & $18.11(8)$ & $13.00(8)$ & 15.62 & 14.18 \\
\hline PodLen (mm) & PM375 & 0.007 & 9.19 & 11.5 & $35.22(9)$ & $24.8(9)$ & 32.39 & 29.61 \\
\hline 100SdWgt (g) & PM375 & 0.004 & 10.17 & 0 & $85.58(8)$ & $48.58(8)$ & 75.56 & 65.44 \\
\hline PodLen (mm) & pPGPSeq8D & 0.006 & 9.50 & 0 & $35.22(9)$ & $24.80(9)$ & 32.12 & 29.38 \\
\hline NPodsPlt & Ah-041 & 0.001 & 12.47 & 0 & $101.3(9)$ & $14.50(9)$ & 60.24 & 40.65 \\
\hline PItWgt (g) & Ah-041 & 0.004 & 10.10 & 0 & $139.3(9)$ & $19.39(10)$ & 76.53 & 53.40 \\
\hline Maturity \% & PM45 & 0.0001 & 17.69 & 0 & $94.99(9)$ & $18.03(9)$ & 51.86 & 74.38 \\
\hline OilCon \% & PM36 & 0.003 & 11.03 & 16.6 & $50.63(9)$ & $41.50(9)$ & 45.85 & 47.56 \\
\hline
\end{tabular}

* Values in the parenthesis indicating the number of individuals constituting each bulk. 
positive correlation with plant weight. In the case of PM375, it is quite possible that one gene has an effect on at least two of the traits, as an increase in seed length could be expected to result in an increased hundred-seed weight, or perhaps these and pod length also. Likewise, for Ah-041, the number of pods could reasonably be expected to influence plant weight.

Two markers themselves, PM45 and PM36, may be linked according to published maps. According to the SSR-based map of the AA genome (Moretzsohn et al. 2005), these two markers were placed very near in the end of fifth linkage group. In the present study, these two markers were each associated with only one trait (percent age of mature pods and oil content, respectively). It is possible that the two QTLs are separated sufficiently that neither marker is linked closely enough to both QTLs for detection, or perhaps the resolution of the BSA approach was not sufficient to identify association to both traits.

\section{Polymorphism}

The percentage of parental polymorphism was $8.9 \%$ in this RIL population. The low level of polymorphism might be due to the low molecular diversity among the parental genotypes. This was in agreement with the previous findings as low level of polymorphism among cultivated groundnut (Halward et al. 1991; Kochert et al. 1991; PaikRo et al. 1992; Stalker et al. 1994; He and Prakash, 1997; Hopkins et al. 1999; Herselman et al. 2003; Moretzsohn et al. 2004; Mace et al. 2006). However, this may be an underestimate of the diversity present in the population, as small (2 bp) differences in size may have not been distinguished reliably using short PAGE gels.

\section{Future direction of work}

Further work is needed to identify additional polymorphism using highly polymorphic markers and to construct a genetic linkage map of this RIL population. As this cross had lower polymorphism than interspecific crosses, the use of more-sophisticated resolving systems such as a DNA fragment analyzer may be used to detect small base pair differences. Further research is also needed to confirming identified QTLs in across the populations. Additional SSR markers have been identified recently (Cuc et al. 2008) or are under development, and these may be expected to improve marker density in the peanut genome.

\section{CONCLUDING REMARKS}

The markers identified in this study, once verified in other peanut genotypes, would allow implementation of markerassisted selection for incorporating the desirable pod and kernel traits.

\section{REFERENCES}

ALTINKUT, A.; KAZAN, K. and GOZUKIRMIZI, N. AFLP marker linked to water-stress-tolerant bulks in barley
(Hordeum vulgare L.). Genetics and Molecular Biology, 2003, vol. 26, no. 1, p. 77-82.

BEAVIS, William D. QTL analyses: power, precision and accuracy. In: PATERSON, A.H. ed. Molecular dissection of complex traits. CRC Press, Boca Raton. 1998, p. 145162.

BENBOUZA, Halima; JACQUEMIN, Jean-Marie; BAUDOIN, Jean-Pierre and MERGEAI, Guy. Optimization of a reliable, fast, cheap and sensitive silver staining method to detect SSR markers in polyacrylamide gels. Biotechnology, Agronomy, Society and Environment, 2006, vol. 10, no. 2, p. 77-81.

BUROW, Mark D.; SIMPSON, Charles E.; PATERSON, Andrew $\mathrm{H}$. and STARR, James L. Identification of peanut (Arachis hypogaea L.) RAPD markers diagnostic of rootknot nematode (Meloidogyne arenaria (Neal) Chitwood) resistance. Molecular Breeding, December 1996, vol. 2, no. 4, p. 369-379.

BUROW, Mark D.; SIMPSON, Charles E.; STARR, James L. and PATERSON, Andrew H. Transmission genetics of chromatin from a synthetic amphidiploid to cultivated peanut (Arachis hypogaea L.): Broadening the gene pool of a monophyletic polyploidy species. Genetics, October 2001, vol. 159, no. 2, p. 823-837.

BUROW, M.D.; STARR, J.L.; PARK, C.H.; SIMPSON, C.E. and PATERSON, A.H. Identification of QTLs for resistance to early leaf spot (Cercospora arachidicola S. Hori) in an introgression population of peanut (Arachis hypogaea L.). In: Proceedings of Plant and Animal Genome XVI Conference. $\left(12^{\text {th }}-16^{\text {th }}\right.$ January, 2008, San Diego, California). Paper no. P424.

CHOI, K.; BUROW, M.D.; CHURCH, G.; BUROW, G.; PATERSON, A.H.; SIMPSON, C.E. and STARR, J.L. Genetics and mechanism of resistance to Meloidogyne arenaria in peanut germplasm. Journal of Nematology, September 1999, vol. 31, no. 3, p. 283-290.

COLLARD, B.C.Y.; JAHUFER, M.Z.Z.; BROUWER, J.B. and PANG, E.C.K. An introduction to markers, quantitative trait loci (QTL) mapping and marker-assisted selection for crop improvement: The basic concepts. Euphytica, January 2005, vol. 142, no. 1-2, p. 169-196.

CUC, Luu M.; MACE, Emma S.; CROUCH, Jonathan H.; QUANG, Vu D.; LONG, Tran D. and VARSHNEY, Rajeev K. Isolation and characterization of novel Microsatellite markers and their application for diversity assessment in cultivated groundnut (Arachis hypogea L.). BMC Plant Biology, May 2008, vol. 8, no. 55.

Food and Agriculture Organization of the United Nations (FAOSTAT). 2007. [30 March, 2009]. Available from Internet: http://faostat.fao.org/site/567/default.aspx 
FERGUSON, M.E.; BUROW, M.D.; SCHULZE, S.R.; BRAMEL, P.J.; PATERSON, A.H.; KRESOVICH, S. and MITCHELL, S. Microsatellite identification and characterization in peanut (A. hypogaea L.). Theoretical and Applied Genetics, April 2004, vol. 108, no. 6, p. 10641070.

GARCIA, G.M.; STALKER, H.T. and KOCHERT, G. Introgression analysis of an interspecific hybrid population in peanuts (Arachis hypogaea L.) using RFLP and RAPD markers. Genome, February 1995, vol. 38, no. 1, p. 166176.

GARCIA, G.M.; STALKER, H.T.; SCHROEDER, E.; LYERLY, J.H. and KOCHERT, G. A RAPD-based linkage map of peanut based on a backcross population between the two diploid species Arachis stenosperma and A. cardenasii. Peanut Science, January-June 2005, vol. 32, no. 1, p. 1-8.

GOMES, R.L.F. and LOPEZ, A.C.D.A. Correlation and path analysis in peanut. Crop Breeding and Applied Biotechnology, 2005, vol. 5, no. 11, p. 105-110.

GOMEZ, S.M.; $\quad$ DENWAR, N.N.; RAMASUBRAMANIAN, T.; BUROW, G.B.; BURKE, J.J.; NAVEEN, P. and BUROW, M.D. Identification of peanut hybrids using microsatellite markers and horizontal polyacrylamide gel electrophoresis. Peanut Science, JulyDecember 2008, vol. 35, no. 2, p. 123-129.

HALWARD, T.M.; STALKER, H.T.; LARUE, E. and KOCHERT, G. Genetic variation detectable with molecular markers among unadapted germplasm resources of cultivated peanut and related wild species. Genome, December 1991, vol. 34, no. 6, p. 1013-1020.

HALWARD, T.; STALKER, H.T. and KOCHERT, G. Development of an RFLP linkage map in diploid peanut species. Theoretical and Applied Genetics, November 1993, vol. 87, no. 3, p. 379-384.

HE, Gouhao and PRAKASH, Channapatna S. Identification of polymorphic DNA markers in cultivated peanut (Arachis hypogaea L.). Euphytica, October 1997, vol. 97, no. 2, p. 143-149.

HERSELMAN, Liezel. Genetic variation among southern African cultivated peanut (Arachis hypogaea L.) genotypes as revealed by AFLP analysis. Euphytica, September 2003, vol. 133, no. 3, p. 319-327.

HERSELMAN, L.; THWAITES, R.; KIMMINS, F.M.; COURTOIS, B.; VAN DER MERWE, P.J.A. and SEAL, S.E. Identification and mapping of AFLP markers linked to peanut (Arachis hypogaea L.) resistance to the aphid vector of groundnut rosette disease. Theoretical and Applied Genetics, November 2004, vol. 109, no. 7, p. 1426-1433.
HOLBROOK, C. Corley and STALKER, H. Thomas. Peanut breeding and genetic resources. Plant Breeding Reviews, 2003, vol. 22, p. 297-356.

HOPKINS, M.S.; CASA, A.M.; WANG, T.; MICHELL, S.E.; DEAN, R.E.; KOCHERT, G.D. and KRESOVICH, S. Discovery and characterization of polymorphic simple sequence repeats (SSRs) in peanut. Crop Science, July 1999, vol. 39, no. 4, p. 1243-1247.

KOCHERT, G.; HALWARD, T.; BRANCH, W.D. and SIMPSON, C.E. RFLP variability in peanut (Arachis hypogaea L.) cultivars and wild species. Theoretical and Applied Genetics, May 1991, vol. 81, no. 5, p. 565-570.

KRIS-ETHERTON, Penny M.; PEARSON, Thomas A.; WAN, Ying; HARGROVE, Rebecca L.; MORIARTY, Kristine; FISHELL, Valerie and ETHERTON, Terry D. High-monounsaturated fatty acid diets lower both plasma cholesterol and triacylglycerol concentrations. American Journal of Clinical Nutrition, December 1999, vol. 70, no. 6, p. 1009-1015.

MACE, E.S.; PHONG, D.T.; UPADHYAYA, H.D.; CHANDRA, S. and CROUCH, J.H. SSR analysis of cultivated groundnut (Arachis hypogaea L.) germplasm resistant to rust and late leaf spot diseases. Euphytica, December 2006, vol. 152, no. 3, p. 317-330.

MICHELMORE, R.W.; PARAN, I. and KESSELI, R.V. Identification of markers linked to disease-resistance genes by bulked segregant analysis: A rapid method to detect markers in specific genomic regions by using segregating populations. Proceedings of the National Academy of Sciences of the United States of America, 1991, vol. 88, no. 21, p. 9828-9832.

MONDAL, S.; GHOSH, S. and BADIGANNAVAR, A.M. RAPD polymorphism among groundnut genotypes differing in disease reaction to late leaf spot and rust. International Arachis Newsletter, 2005, vol. 25, p. 25-30.

MOORE, K.M. and KNAUFT, D.A. The inheritance of high oleic acid in Peanut. Journal of Heredity, May 1989, vol. 80, no. 3, p. 252-253.

MORETZSOHN, Marcio C.; HOPKINS, Mark S.; MITCHELL, Sharon E.; KRESOVICH, Stephen; VALLS, Jose Francisco M. and FERREIRA, Marcio. Genetic diversity of peanut (Arachis hypogaea L.) and its wild relatives based on the analysis of hypervariable regions of the genome. BMC Plant Biology, July 2004, vol. 4, no. 11.

MORETZSOHN, M.C.; LEOI, L.; PROITE, K.; GUIMARÃES, P.M.; LEAL-BERTIOLI, S.C.M.; GIMENES, M.A.; MARTINS, W.S.; VALLS, J.F.M.; GRATTAPAGLIA, D. and BERTIOLI, D.J. A microsatellite-based, gene-rich linkage map for the AA genome of Arachis (Fabaceae). Theoretical and Applied Genetics, October 2005, vol. 111, no. 6, p. 1060-1071. 
PAIK-RO, O.G.; SMITH, R.L. and KNAUFT, D.A. Restriction fragment length polymorphism evaluation of six peanut species within the Arachis section. Theoretical and Applied Genetics, June 1992, vol. 84, no. 1-2, p. 201-208.

POWELL, Wayne; MACHRAY, Gordon C. and PROVAN, Jim. Polymorphism revealed by simple sequence repeats. Trends in Plant Science, July 1996, vol. 1, no. 7, p. 215222.

RAINA, S.N.; RANI, V.; KOJIMA, T.; OGIHARA, Y.; SINGH, K.P. and DEVARUMATH, R.M. RAPD and ISSR fingerprints as useful genetic markers for analysis of genetic diversity, varietal identification, and phylogenetic relationships in peanut (Arachis hypogaea L.) cultivars and wild species. Genome, October 2001, vol. 44, no. 5, p. 763772.

SAMIZADEH, H.; YAZDI-SAMADI, B.; GHANNADHA, M.R.; MALBOBI, M.A.; TALEEI A.R. and RICE STINGAM, G. A study of molecular marker associated with pod length trait in canola (B. napus) double haploid population. Iranian Journal of Agricultural Sciences, 2003, vol. 34, no. 4, p. 871-879.

SIMPSON, C.E.; BARING, M.R.; SCHUBERT, A.M.; MELOUK, H.A.; BLACK, M.C.; LOPEZ, Y. and KEIM, K.A. Registration of 'Tamrun OL01' peanut. Crop Science, November 2003, vol. 43, no. 6, p. 2298.

SINGH, A.K. and SIMPSON, C.E. Biosystematics and genetic resources. In: SMARTT, J. ed. The groundnut crop: a scientific basis for improvement. London; Chapman and Hall, 1994, p. 96-137.

STALKER, H.T.; PHILLIPS, T.D.; MURPHY, J.P. and JONES, T.M. Variation of isozyme patterns among Arachis species. Theoretical and Applied Genetics, January 1994, vol. 87, no. 6, p. 746-755.

STALKER, H.T. and MOZINGO, L.G. Molecular markers of Arachis and marker- assisted selection. Peanut Science, April 2001, vol. 28, p. 117-123.

SUBRAMANIAN, V.; GURTU, S.; RAO, R.C.N. and NIGAM, S.N. Identification of DNA polymorphism in cultivated groundnut using random amplified polymorphic DNA (RAPD) assay. Genome, August 2000, vol. 43, no. 4, p. 656-660.

WENZL, Peter; RAMAN, Harsh; WANG, Junping; ZHOU, Meixue; HUTTNER, Erich and KILIAN, Andrzej. A DArT platform for quantitative bulked segregant analysis. BMC Genomics, June 2007, vol. 8, p. 196.

WILLIAMS, E.J. and DREXLER, J.S. A non-destructive method for determining peanut pod maturity. Peanut Science, 1981, vol. 8, p. 134-141.
YONG, L.; BOSHOU, L.; WANG, S.Y.; DONG, L. and JIANG, H. Identification of AFLP markers for resistance to seed infection by Aspergillus flavus in peanut (Arachis hypogaea L.). Acta Agronomica Sinica, 2005, vol. 31, p. 1349-1353. 